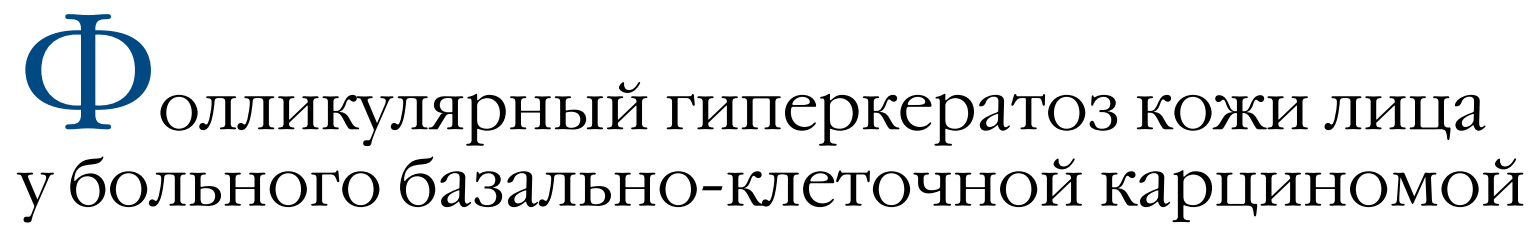

М.В. Жучков, Ю.С. Бычкова, М.А. Тарасова

ГБУ Рязанской области «Областной клинический кожно-венерологический диспансер» 390046, г. Рязань, ул. Спортивная, д. 9

В данной статье приводится клиническое наблюдение паранеопластического синдрома у пациента с базальноклеточной карциномой кожи. Авторы приводят клинические особенности данного описанного впервые паранеопластического ретенционного фолликулярного гиперкератоза области лица.

Ключевые слова: базалиома, паранеопластический синдром, дерматоскопия, фолликулярный гиперкератоз.

Контактная информация: misha.juchkov@gmail.com. Вестник дерматологии и венерологии 2016; (5): 39—43.

\title{
F acial skin follllicular hyperkeratosis of patients with basal cell carcinoma
}

\author{
M.V. Zhuchkov, Yu.S. Bychkova, M.A. Tarasova
}

Ryazan Regional Clinical Skin and Venereal Diseases Dispensary

Sport str., 9, Ryazan, 390046, Russia

This article provides a clinical observation of paraneoplastic syndrome of a patient with basal cell carcinoma of skin. Authors present clinical features of the described for the first time, paraneoplastic retentional follicular hyperkeratosis of facial area.

Key words: basal cell carcinoma, paraneoplastic syndrome, dermatoscopy, follicular hyperkeratosis. 
Базально-клеточная карцинома является одной из наиболее распространенных злокачественных опухолей кожи человека. Со времени исторически первого описания ulcus rodens известным исследователем и патологом A. Jacob прошло более 140 лет. За этот весьма продолжительный отрезок времени основные аспекты этиологии, канцерогенеза, гистоморфологической диагностики, медикаментозной и хирургической терапии базалиомы кожи были изучены практически досконально [1]. К основным фракторам риска возникновения этого вида немеланоцитарного рака кожи относятся кумулятивная доза УФ-излучения, наличие I и II типов кожи по классификации Томаса Фитцпатрика, плохая восприимчивость к загару [2]. Несмотря на чрезвычайную редкость метастазирования и хорошие эстетические результаты радикального лечения ранних форм базалиомы, классические исследования Bower и соавт. продемонстрировали, что факт выявления хотя бы одного очага базально-клеточного рака кожи у пациента является независимым фактором риска развития меланомы кожи в течение жизни [3].

Базально-клеточный рак кожи является одной из тех опухолей, канцерогенез которой неразрывно связан с кумулятивным воздействием УФ-излучения, хотя некоторые разрозненные исследования говорят о большем влиянии получения пациентом не кумулятивных, а кратковременных высоких доз УФизлучения в диапазоне спектра 290-320 нм [4]. Продемонстрирована также роль генных мутаций и воздействия ионизирующей радиации в патогенезе базалиом кожи [5]. При некоторых редко встречающихся клинических синдромах, таких как синдромы Горлина - Гольца, Базе и Ромбо, имеет место предрасположенность к развитию первично множественных базально-клеточных карцином кожи [6]. Вклад иммуносупрессии в канцерогенез данного вида опухоли сомнителен, учитывая отсутствие статистически значимого увеличения количества выявленных базалиом (но не плоскоклеточных карцином) у пациентов с лейкозом и/или перенесших трансплантацию костного мозга в большинстве исследований [7]. Являясь злокачественным (хотя и не метастазирующим) новообразованием кожи, базалиома теоретически может быть ассоциирована с паранеопластическим синдромом, вторичным по отношению к пролиферации атипичных базалоидных клеток опухоли. Но до настоящего времени таких случаев паранеопластического фолликулярного гиперкератоза в мировой периодической литературе не описано.

Тем не менее фолликулярный гиперкератоз как паранеопластический синдром был описан при миеломной болезни Рустицкого - Калера и как одиночное вторичное кожное проявление пролиферации атипичных плазматических клеток крови, и в сочетании с криоглобулинемией $[8,9]$.
Любой паранеопластический дерматоз (синдром) должен удовлетворять двум важнейшим диагностическим критериям: во-первых, он должен быть ассоциирован именно со злокачественным новообразованием, пусть даже протекающим латентно, и, во-вторых, он должен демонстрировать «клиническую параллельность» течению данного злокачественного патологического процесса [10].

\section{Клинический случай}

Пациент Н. обратился за медицинской помощью в ГБУ РО «ОККВД» по поводу высыпаний в области лица, не беспокоящих его субъективно. Анамнестически указанные высыпания существуют около двух лет, не меняя своей морфологии, но захватывая все большую площадь поверхности кожи лица. При осмотре эффрлоресценции представлены фолликулярными гиперкератотическими очагами («шипами»), клинически напоминающими «кожный рог» (рис. 1, 2). В центре некоторых таких элементов определялись растущие параллельно с ними щетинковые волосы.

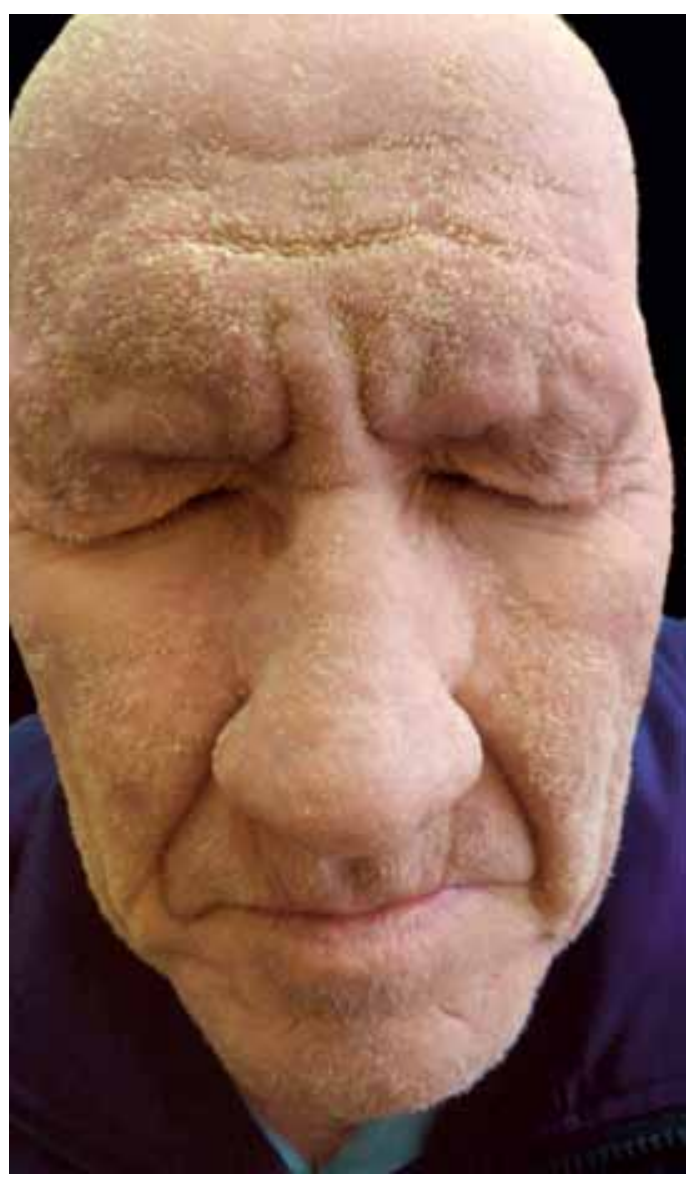

Рис. 1. Фолликулярные гиперкератотические эффолоресценции 


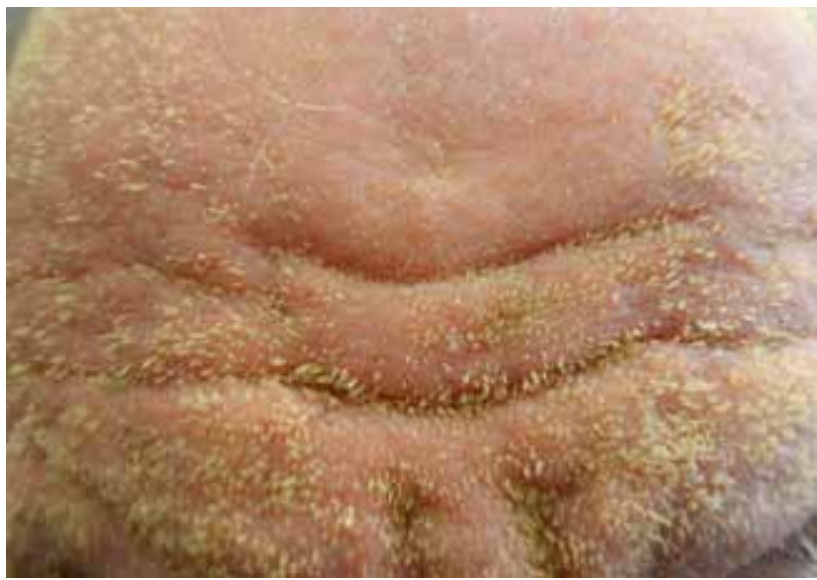

Рис. 2. Фолликулярные гиперкератотические эффолоресценции: область лба
Примечательным моментом наблюдения является тот факт, что пациент на протяжения всего периода наличия высыпаний не применял бритву не из-за страха травмировать высыпания, а из-за отсутствия потребности в ней. Высыпания мономорфны, расположены в той или иной степени по всему лицу, но при этом они не выходят за его пределы. Анамнестически было выяснено, что за несколько месяцев до начала данного заболевания в области левой щеки появился узелковый элемент телесного цвета плотной консистенции, также не демонстрировавший никаких субъективных ощущений (рис. 3). Пациентом данный очаг был трактован как доброкачественное образование, и поэтому за своевременной медицинской помощью он все это время не обращался. За два года существования заболевания этот нодулярный очаг, со слов пациента, значительно увеличился в размерах, но, несмотря на это, не беспокоил его. При осмотре в области различных участков кожного покрова лица определяются гиперкератотические конусовидные элементы, берущие начало из устьев волосяных фролликулов (рис. 4). В центре некоторых гиперкератотических эфролоресценций определяются сохранившиеся щетинковые волосы. При проведении дерматоскопии нодулярного очага определяются многочисленные серпантинные сосуды, расположенные разветвленно. Кроме того, в нижней части дерматоскопического изображения определяются единичные серые и голубые комки (англ. clods), также являющиеся весьма чувствительными и специфичными признаками базально-клеточного рака кожи (рис. 5). Диагноз базалиомы кожи был окончательно вериорицирован только после проведения эксцизионной биопсии и патогистологического исследования удаленного новообразования.

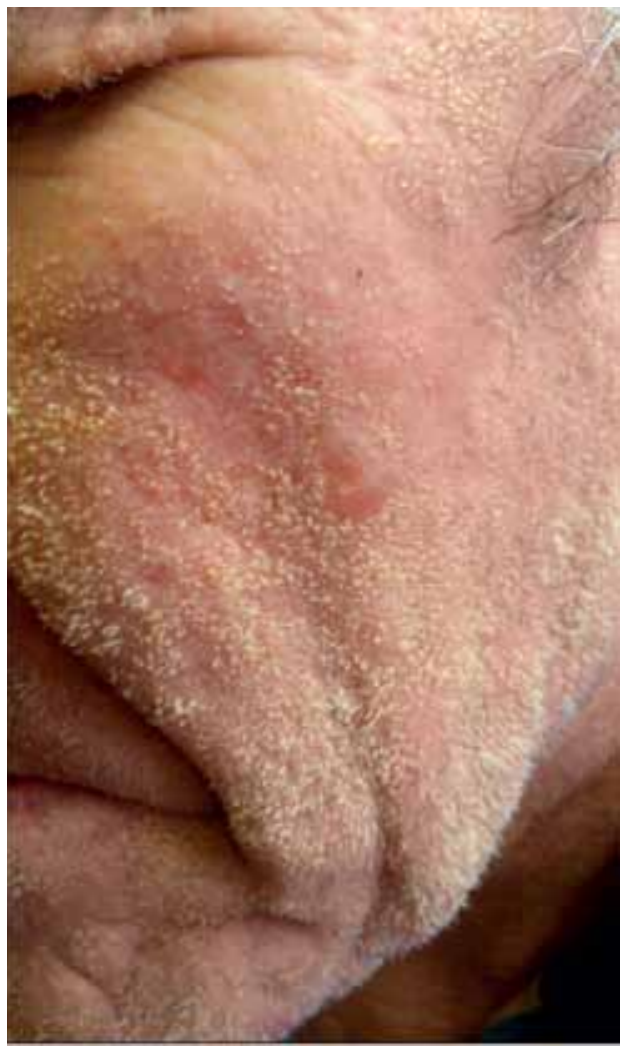

Рис. 3. Нодулярная базально-клеточная карцинома кожи (область щеки)

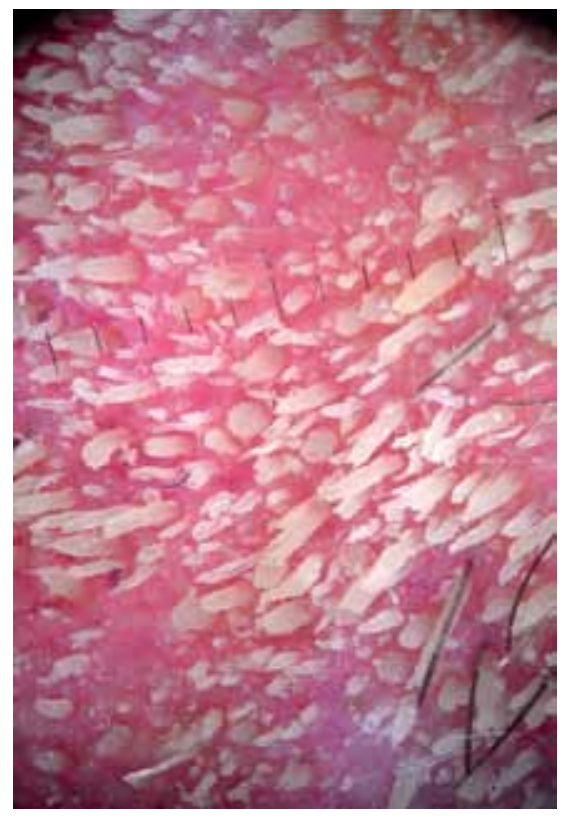

Рис. 4. Дерматоскопическое изображение: фолликулярный гиперкератоз 


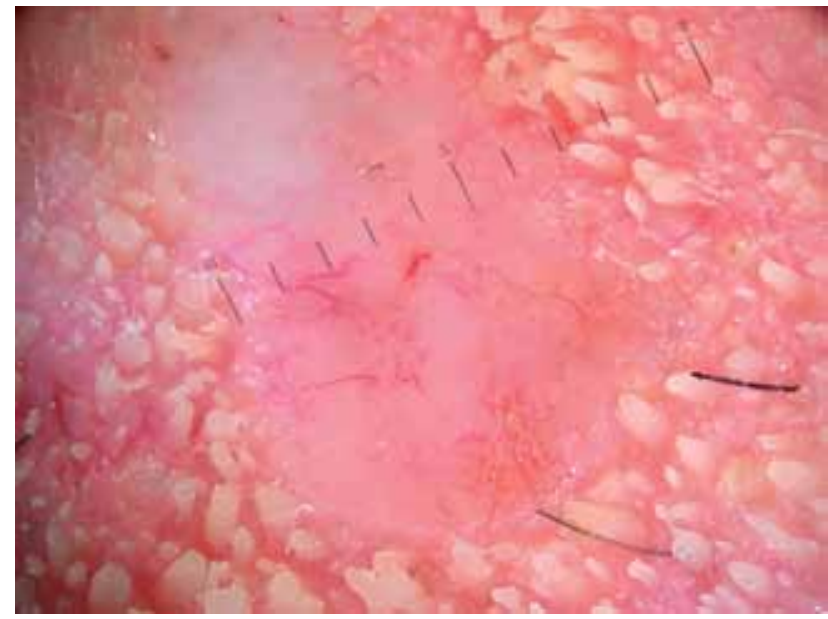

Рис. 5. Дерматоскопическое изображение: базалиома

При исследовании микропрепарата новообразования кожи щеки определялся нодулярный очаг пролиферации атипичных базалоидных опухолевых клеток с оптически плотным ядерным хроматином, участками «щелей» между стромой и подлежащей тканью и умеренным полиморфно-клеточным инфильтратом вокруг границ опухоли. В микропрепарате из участка кожи с признаками фолликулярного гиперкератоза определялись значительно расширенные волосяные фолликулы, заполненные кератиновыми, местами паракератотическими массами с умеренной лимфоцитарной инфильтрацией вокруг почти всей длины фолликулярного канала. Кроме того, в верхней части дермы отмечался умеренный лимфоцитарный периваскулярный инфильтрат.

Спустя 3 нед. после эксцизии нодулярной базалиомы у пациента был констатирован полный клинический регресс гиперкератотических высыпаний в области лица. Спустя еще 2 нед. на коже лица возобновился рост щетинковых волос в области бороды.

Пациент был всесторонне обследован врачами терапевтом, фтизиатром, инфекционистом, гематологом и, главное, онкологом для исключения иных причин (кроме базалиомы), потенциально способных быть источниками такого рода эффлоресценций, в том числе злокачественных новообразований других локализаций.

\section{Обсуждение}

С учетом четкой временной ассоциации гиперкератотических элементов с базально-клеточным раком кожи, а также полного регресса эфрфлоресценций после эксцизии нодулярной базалиомы возникшие у пациента Н. явления распространенного фролликулярного гиперкератоза можно трактовать как паранеопластический синдром. До настоящего времени описания такого рода паранеоплазии, ассоциированной с базально-клеточным раком кожи, в мировой периодической литературе не встречалось.

В данном клиническом наблюдении безусловный интерес представляет не первичный очаг базалиомы, очевидный в клиническом, дерматоскопическом и патогистологическом плане, а вторичный паранеопластический синдром, возникший у данного пациента спустя непродолжительное время после дебюта злокачественной опухоли кожи.

Описанный вид паранеопластического синдрома проявляется относительно распространенным фролликулярным, вероятно, ретенционным гиперкератозом, замедляющим или временно останавливающим рост анагеновых волос в фолликулах. Дискутабельным остается вопрос о том, является ли определяемый клинически транзиторный гипотрихоз первичным явлением, т.е. вторым после фолликулярного гиперкератоза компонентом описываемого паранеопластического синдрома, или же он вторичен по отношению к ретенции кератотических масс в волосяном фолликуле. Так или иначе, поскольку это первое клиническое описание такого рода симптомокомплекса, однозначный ответ на этот вопрос дать не представляется возможным.

\section{Заключение}

Бесспорный интерес данного клинического наблюдения определяется двумя обстоятельствами. Во-первых, впервые в периодической литературе описывается паранеопластический фолликулярный гиперкератоз при базально-клеточной карциноме кожи. До настоящего времени указанный тип паранеоплазии выявлялся только у пациентов с болезнью Рустицкого - Калера. Во-вторых, сам фракт формирования паранеопластического синдрома при эпителиальном злокачественном новообразовании кожи - практически не изученная проблема фундаментальной и клинической дерматологии, заставляющая нас еще раз обратить внимание на особенности канцерогенеза при базально-клеточном раке кожи. 


\section{Литература}

1. Li C., Athar M. Ionizing Radiation Exposure and Basal Cell Carcinoma Pathogenesis. Radiation Research 2016; 185 (3): 217-228.

2. Wu S. et al. History of Severe Sunburn and Risk of Skin Cancer Among Women and Men in 2 Prospective Cohort Studies. American Journal of Epidemiology 2016; 183 (9): 824—833.

3. Bower C.P. et al. Basal cell carcinoma and risk of subsequent malignancies: A cancer registrybased study in southwest England. Journal of the American Academy of Dermatology 2000; 42 (6): 988-991.

4. Masud D., Moustaki M., Staruch R., Dheansa B. Basal cell carcinomata: Risk factors for incom- plete excision and results of re-excision. Journal of Plastic, Reconstructive \& Aesthetic Surgery. 2016; 69 (5): 652—656.

5. Clark C.M., Furniss M., Mackay-Wiggan J.M. Basal cell carcinoma: an evidence-based treatment update. Am J Clin Derm 2014; 15 (3): 197-216.

6. Khalesi M. et al. Basal cell carcinomas on sunprotected vs. sun-exposed body sites: a comparison of phenotypic and environmental risk factors. Photodermatol Photoimmunol Photomed 2015; 31 (4): 202-211.

7. Maly T.J., Sligh J.E. Defining locally advanced Basal cell carcinoma. Journal Drugs Derm 2014; $13(5): 528-529$.
8. Lukitsch 0., Gebhardt K.P., Kövary P.M. Follicular hyperkeratosis and cryocrystalglobulinemia syndrome. Occurrence in a patient with multiple myeloma. Arch Derm 1985; 121 (6): 795-798.

9. Bork K., Böckers M., Pfeifle J. Pathogenesis of paraneoplastic follicular hyperkeratotic spicules in multiple myeloma. Follicular and epidermal accumulation of $\mathrm{Ig}$ dysprotein and cryoglobulin. Arch Derm 1990;126 (4): 509-513.

10. Weenig R.H., Mehrany K. Dermal and pannicular manifestations of internal malignancy. Derm Clin 2008; 26 (1): 31—43.

об авторах:

М.В. Жучков — врач-дерматовенеролог, зам. главного врача ГБУ РО «Областной клинический кожно-венерологический диспансер», Рязань

Ю.С. Бычкова - врач-дерматовенеролог ГБУ РО «Областной клинический кожно-венерологический диспансер», Рязань

М.А. Тарасова — к.м.н., главный врач ГБУ РО «Областной клинический кожно-венерологический диспансер», Рязань

\section{Конфликт интересов}

Авторы заявляют об отсутствии потенциального конфликта интересов, требующего раскрытия в данной статье 